\title{
Helmet Versus Nasal-Prong CPAP in Infants With Acute Bronchiolitis
}

\author{
Juan Mayordomo-Colunga MD PhD, Corsino Rey MD PhD, Alberto Medina MD PhD, \\ Pablo Martínez-Camblor PhD, Ana Vivanco-Allende MD PhD, and Andrés Concha MD PhD
}

\begin{abstract}
BACKGROUND: Nasal prongs are frequently used to deliver noninvasive CPAP in bronchiolitis, especially in the youngest children. A helmet interface is an alternative that might be comparable to nasal prongs. We sought to compare these interfaces. METHODS: We performed a prospective, randomized, crossover, single-center study in an 8-bed multidisciplinary pediatric ICU in a university hospital. Infants age $<3$ months who were consecutively admitted to the pediatric ICU during a bronchiolitis epidemic season and fulfilled inclusion criteria were recruited. Subjects were randomly allocated to receive CPAP via a helmet or nasal prongs for $60 \mathrm{~min}$. The subjects were then placed on the other CPAP system for another 60-min period (helmet then nasal prongs [H-NP] or nasal prongs then helmet $[\mathrm{NP}-\mathrm{H}])$. Measurements were taken at 30, 60, 90, and $120 \mathrm{~min}$. Failure was defined as the need for further respiratory support. RESULTS: Sixteen subjects were included, with 9 in the H-NP group and 7 in the NP-H group. CPAP significantly reduced respiratory distress, showing no differences between the H-NP and NP-H groups in terms of improving the Modified Wood's Clinical Asthma Score from $4.8 \pm 1$ to $3 \pm 0.9$ and $2.7 \pm 1.7$ points at 60 min and 120 min in the H-NP group, respectively, and from $4.2 \pm 0.9$ to $2.8 \pm 0.9$ and to $2.9 \pm 0.9$ at $60 \mathrm{~min}$ and 120 min, respectively, in the NP-H group. Sedatives were used in only 3 subjects ( 2 in the NP-H group, $P=.77$ ). The failure rate was similar in both groups ( 3 of 9 subjects vs 3 of 7 subjects, $P=.70)$. No significant differences were seen for heart rate, breathing frequency, $\mathrm{F}_{\mathrm{IO}_{2}}$, or transcutaneous oxygen saturation response. CONCLUSIONS: Our results suggest that CPAP delivered by nasal prongs and CPAP delivered by helmet are similar in terms of efficacy in young infants with acute bronchiolitis. Key words: bronchiolitis; continuous positive airway pressure; noninvasive ventilation; helmet; nasal prongs; infants. [Respir Care 2018;63(4):455-463. () 2018 Daedalus Enterprises]
\end{abstract}

\section{Introduction}

Bronchiolitis is the leading cause of admission in children younger than $1 \mathrm{y}$ worldwide. No effective treatments are available, apart from hydration, oxygen, and upper airway suctioning if needed. ${ }^{1}$ Noninvasive CPAP has been proven to be effective as a respiratory support in moderate to severe bronchiolitis ${ }^{2}$ to avoid invasive ventilation by

\footnotetext{
Drs Mayordomo-Colunga, Rey, Medina, Vivanco-Allende, and Concha are affiliated with the Pediatric Intensive Care Unit, Department of Pediatrics, Hospital Universitario Central de Asturias, University of Oviedo, Oviedo, Spain. Dr Martínez-Camblor is affiliated with the Geisel School of Medicine at Dartmouth, Dartmouth College, Hanover, New Hampshire, and with the Universidad Autónoma de Chile, Santiago, Chile.
}

The authors have disclosed no conflict of interest. decreasing respiratory muscles upload $^{3}$ and maintaining patency of the lower airways. CPAP is usually delivered via nasal prongs or a nasal mask. ${ }^{2,4}$ However, the effectiveness of nasal CPAP might be limited due to air leakage through the child's mouth, airway obstruction from secretions, or nasal injury. ${ }^{5,6}$

A helmet interface has been proposed as an alternative to nasal administration of CPAP in infants and preschool children with acute respiratory failure, ${ }^{7-12}$ in preterm

\footnotetext{
Correspondence: Juan Mayordomo-Colunga MD PhD, Sección de Cuidados Intensivos Pediátricos, Área de Gestión Clínica de Pediatría, Hospital Universitario Central de Asturias, Avda. de Roma s/n 33011, Oviedo, Asturias, Spain. E-mail: jmcolunga@ hotmail.com.
}

DOI: $10.4187 /$ respcare. 05840 
infants, ${ }^{13}$ and also in infants suffering bronchiolitis in conjunction with heliox. ${ }^{14}$ Furthermore, helmet-delivered CPAP has shown increased tolerance and increased effectiveness when compared to face mask in a crossover study ${ }^{7}$ and in infants with acute respiratory failure. ${ }^{8} \mathrm{~A}$ recent multi-center randomized controlled trial in respiratory syncytial virus bronchiolitis also described better tolerance and less need of sedation when using the helmet compared with the face mask, although intubation rates did not differ. ${ }^{9}$ Helmet CPAP has also been compared to high-flow nasal cannula oxygenation in mild to moderate respiratory distress in children $<2$ y old, with similar results reported. ${ }^{12}$

Small infants with bronchiolitis requiring respiratory support have been treated in our pediatric ICU with CPAP by means of the helmet interface and nasal prongs, as in other studies. ${ }^{7,12,14-17}$ The objective of this study was to compare the effectiveness of CPAP delivered via a helmet or via nasal prongs in terms of clinical assessment of the work of breathing.

\section{Methods}

\section{Subjects}

Subjects were consecutively admitted infants under 3 months of age diagnosed with bronchiolitis, with a Modified Wood's Clinical Asthma Score (M-WCAS) $\geq 4$, venous $\mathrm{P}_{\mathrm{CO}_{2}} \geq 60 \mathrm{~mm} \mathrm{Hg}$, or $\mathrm{S}_{\mathrm{pO}_{2}}<92 \%$ despite nebulized adrenalin for at least $1 \mathrm{~h}$ (modified from MartinónTorres ${ }^{16}$ ). The diagnosis of bronchiolitis was made if a child with a previous upper respiratory infection became tachypneic and exhibited prolonged expiratory time, wheezing, rales, respiratory accessory muscle activation, and hyperinflation on chest radiograph. ${ }^{18}$

Exclusion criteria included cardiorespiratory arrest, neurological impairment with inability to maintain airway patency, hemodynamic instability, inability to manage secretions despite frequent suctioning, undrained pneumothorax, cyanotic congenital heart disease, severe pulmonary condition, and immune deficiencies.

This research project was approved by the Research Ethics Committee of Hospital Universitario Central de Asturias. Written informed consent was obtained from subjects' parents or guardians.

\section{Definitions}

CPAP failure was defined as the need to intubate the infant or switch to noninvasive ventilation (NIV) due to worsening clinical condition. Major adverse events were defined as the appearance of hemodynamic instability, severe arrhythmias, barotrauma (eg, pneumothorax, pneumomediastinum, or massive subcutaneous emphysema),

\section{QUICK LOOK}

\section{Current knowledge}

Bronchiolitis is one of the most substantial health burdens for infants worldwide. Management is supportive, focusing on maintaining oxygenation and hydration of the patient. CPAP has been proven to be effective as a respiratory support in moderate to severe bronchiolitis. There are several interfaces available to deliver CPAP.

\section{What this paper contributes to our knowledge}

Infants with bronchiolitis were randomized to receive CPAP via one interface and then another (helmet followed by nasal prongs, or nasal prongs followed by helmet). Sedation use, CPAP duration, CPAP failure rates, and clinical variables were similar between groups. Both methods of CPAP delivery were found to be equally effective at reducing respiratory distress.

and hypercapnic coma. Other adverse events considered to be mild or moderate were pressure sores, gastric distention, and conjunctivitis.

\section{Study Protocol}

Subjects were kept in a semirecumbent position, and suctioning of secretions was performed as needed. The first subject was randomly allocated to receive CPAP either by means of a helmet interface (CaStar; Starmed, Mirandola, Italy) or nasal prongs (Infant Flow driver, Viasys, Conshohocken, Pennsylvania) for $60 \mathrm{~min}$. Subsequent subjects included in the study were alternatively allocated to receive helmet-delivered CPAP or CPAP via nasal prongs in the first period. After the first $60 \mathrm{~min}$, a careful suctioning of secretions was performed, and subjects were then placed on the other CPAP system for another 60-min period. Measurements were taken at baseline and at 30,60, 90, and $120 \mathrm{~min}$. The group in which CPAP was initially delivered by helmet followed by nasal prongs was named the H-NP group. The other cohort was named the NP-H group.

After this 120-min period, CPAP was maintained with the system used in the second phase of the study for as long as considered necessary by the clinician in charge. If a subject's clinical condition worsened at any time, such as with increasing respiratory distress, hypoxemia, hypercapnia, or exhaustion, the attending physician decided whether to change to NIV by means of a face mask or to intubate the subject. 


\section{CPAP Equipment}

When using the helmet interface, CPAP was delivered via a noninvasive ventilator (CF 800; Dräger, Lübeck, Germany) connected to an air-oxygen port at a flow of $30 \mathrm{~L} / \mathrm{min}$ with the intent to avoid rebreathing. ${ }^{19} \mathrm{~A}$ soft cushion was placed inside the helmet to avoid pressure sores on the neck or occipital region. When using nasal prongs, the CPAP system was the Infant Flow driver (Viasys).

Initial optimal CPAP was set to maintain $\mathrm{S}_{\mathrm{pO}_{2}}>92 \%$ using the lowest $\mathrm{F}_{\mathrm{IO}_{2}}$. Minimum CPAP was set at $5 \mathrm{~cm} \mathrm{H}_{2} \mathrm{O}$. A cascade-type heated humidifier was used in all cases (MR850, Fisher \& Paykel, Auckland, New Zealand). A gastric tube was inserted in all subjects to avoid gastric distention and to feed a subject when possible.

If a subject appeared distressed, intravenous midazolam boluses were administered $(0.05-0.10 \mathrm{mg} / \mathrm{kg})$, and, if needed, a continuous perfusion was started $(0.05-0.10 \mathrm{mg} / \mathrm{kg} / \mathrm{h})$. No subject received any nebulized medications, systemic corticosteroids, or caffeine. The need for sedation and the occurrence of adverse events was also recorded. A nasopharyngeal swab specimen was tested for respiratory syncytial virus in all cases.

\section{End Points}

The primary end point was to compare the clinical response of the H-NP group with that of the NP-H group in terms of the M-WCAS. Secondary end points included the comparison of other variables (ie, heart rate, breathing frequency, $\mathrm{S}_{\mathrm{pO}_{2}}$, and $\mathrm{F}_{\mathrm{IO}_{2}}$ ) and the variation percentage to initial value (VPIV) of these figures between both groups. Other secondary end points were the comparison of CPAP failure, the occurrence of adverse events, and the use of sedatives between the groups.

\section{Statistical Analysis}

Following Grizzle's study, we analyzed the possible carryover effect, as well as the period effect. ${ }^{20}$ The normal distribution of variables was assessed using the ShapiroWilk test. A paired $t$ test was performed to analyze differences between both treatment groups. The evolution of variables was measured at each moment as VPIV. Given a moment 1 and a variable $\mathrm{A}$, the variation percentage of variable A at moment 1 (AVP1) was measured according to the formula $\mathrm{AVP} 1=100 \times(\mathrm{A} 1-\mathrm{A} 0) / \mathrm{A} 0$, where $\mathrm{A} 0$ is the initial value of variable $\mathrm{A}$.

Sample size was calculated based on M-WCAS and was computed to detect mean differences between helmet and nasal CPAP patients of over $15 \%$ with a power of 0.8 ( 1 - type- 2 error) and a type- 1 error of 0.05 . Based on a previous pilot study, we assumed that M-WCAS ranged from $10 \%$ to $20 \%$, resulting in a minimum sample size of 7 per group.

\section{Results}

A total of 17 subjects fulfilled the inclusion criteria and completed the crossover study period; 1 subject was excluded because he was diagnosed with cystic fibrosis after admission. No subject required intubation or switching to NIV during the 2-h study period, and no apneas requiring intervention were registered (3 hypopneas in the NP-H group, and 2 hypopneas in the H-NP group). Subject characteristics are shown in Table 1.

In the H-NP group, 1 subject showed poor tolerance of the nasal prongs used in the second part of the study and was switched back to helmet-delivered CPAP nearly $3 \mathrm{~h}$ later. Similarly, 1 subject in to the NP-H group was changed back to nasal-prong CPAP after the crossover study due to poor tolerance of the helmet. No adverse events occurred during the crossover phase. The level of CPAP delivered did not differ between groups with the following values (in $\mathrm{cm} \mathrm{H}_{2} \mathrm{O}$ ): $6.1 \pm 1.2$ at $30 \mathrm{~min}, 6.2 \pm 1$ at $60 \mathrm{~min}$, $6.2 \pm 1.1$ at $90 \mathrm{~min}$, and $6.2 \pm 0.9$ at $120 \mathrm{~min}$.

Two subjects, both in the H-NP group, required intubation. One developed severe hypoxemia due to pneumothorax $6 \mathrm{~h}$ after the crossover phase while receiving nasal prong CPAP. The other subject was changed back to the helmet interface $2 \mathrm{~h}$ after the crossover phase due to increasing distress with the nasal prongs, but $3 \mathrm{~h}$ later he was placed on NIV and was finally intubated $8 \mathrm{~h}$ later. Apart from these 2 subjects, who were eventually intubated, another 4 subjects experienced increasing respiratory distress despite CPAP treatment and were placed on NIV, obviating the need for intubation; 3 subjects belonged to the NP-H group and 1 subject was in the H-NP group. Thus, CPAP failure occurred in 3 cases in each group. Figure 1 presents the distribution of subjects in the study and the clinical outcome in each group. Apart from the previously mentioned pneumothorax, no other adverse events were registered. The duration of CPAP did not differ between the 2 groups. All of the subjects of the study survived.

\section{Clinical Score}

M-WCAS improved significantly from baseline in both the H-NP group and the NP-H group (Fig. 2). In the H-NP group, M-WCAS fell from $4.8 \pm 1$ to $3 \pm 0.9$ at $60 \mathrm{~min}$ $(P<.001)$, and to $2.7 \pm 1.7$ at $120 \min (P<.001)$. In the NP-H group, M-WCAS decreased from $4.2 \pm 0.9$ to $2.8 \pm 0.9$ at $60 \min (P<.001)$, and to $2.9 \pm 0.9$ at $120 \mathrm{~min}(P<.001)$. Figure 2 presents the evolution of the VPIV of M-WCAS during the crossover phase and for $6 \mathrm{~h}$ in both groups. No statistically significant differences were detected in M-WCAS improvement between the 2 groups. 
Table 1. Subject Characteristics

\begin{tabular}{|c|c|c|c|}
\hline Characteristics & H-NP Group $(n=9)$ & NP-H Group $(n=7)$ & $P$ \\
\hline Age, d & $56.7 \pm 14.7$ & $39.7 \pm 13.6$ & .032 \\
\hline Male, $\%$ & 55.6 & 42.9 & .50 \\
\hline Weight, kg & $4.4 \pm 0.7$ & $4.4 \pm 0.8$ & .96 \\
\hline PRISM III score & $2.4 \pm 2.2$ & $2.6 \pm 2$ & .91 \\
\hline RSV isolation in swab specimen, $n$ & 7 & 6 & .69 \\
\hline Baseline M-WCAS & $4.8 \pm 1$ & $4.2 \pm 0.9$ & .24 \\
\hline Prematurity, $n$ & 3 & 0 & .21 \\
\hline Baseline heart rate, beats/min & $169.8 \pm 15.4$ & $175 \pm 15.3$ & .51 \\
\hline Baseline breathing frequency, breaths/min & $56 \pm 12.7$ & $55.3 \pm 9.3$ & .90 \\
\hline $\mathrm{F}_{\mathrm{IO}_{2}}, \%$ & $35.1 \pm 7.2$ & $32 \pm 3$ & .30 \\
\hline $\mathrm{S}_{\mathrm{pO}_{2}}, \%$ & $97 \pm 2.8$ & $95.7 \pm 3.1$ & .41 \\
\hline Baseline venous $\mathrm{P}_{\mathrm{CO}_{2}}, \mathrm{~mm} \mathrm{Hg}$ & $56.3 \pm 13.6$ & $56.4 \pm 4.7$ & .98 \\
\hline Baseline venous $\mathrm{pH}$ & $7.31 \pm 0.06$ & $7.29 \pm 0.08$ & .77 \\
\hline CPAP failure, $n$ & 3 & 3 & .70 \\
\hline Use of sedatives, $n$ & 1 & 2 & .77 \\
\hline CPAP duration, $\mathrm{h}$ & $38.2 \pm 18$ & $55 \pm 39$ & .43 \\
\hline
\end{tabular}

Subjects in the H-NP group received helmet-delivered CPAP first and then nasal CPAP, whereas subjects in the NP-H group received nasal CPAP first and then helmet-delivered CPAP. PRISM $=$ Pediatric Risk of Mortality

RSV $=$ respiratory syncytial virus

M-WCAS = modified Wood's Clinical Asthma Score

\section{Heart Rate}

In H-NP group, the heart-rate VPIV did not reach statistical significance until $6 \mathrm{~h}$. In the NP-H group, heart-rate VPIV significantly decreased from $30 \mathrm{~min}(P=.033)$, and this decrease was maintained throughout the first $6 \mathrm{~h}$. However, there were no significant differences between the 2 groups (Fig. 3).

\section{Respiratory Rate}

Clinical evolution of breathing frequency did not differ at any moment between the study groups (Fig. 4). In the H-NP group, VPIV was already statistically significant at $90 \mathrm{~min}(P=.033)$, while in the NP-H group it did not achieve statistical significance until $6 \mathrm{~h}(P=.01)$. In the $\mathrm{NP}-\mathrm{H}$ group, there was a significant increase in the variation percentage of breathing frequency at $90 \mathrm{~min}$ (after switching to helmet-delivered CPAP at $60 \mathrm{~min}$ ).

$\mathrm{F}_{\mathrm{IO}_{2}}$ and $\mathrm{S}_{\mathrm{pO}_{2}}$

We found no significant percentage variations to initial values for $\mathrm{F}_{\mathrm{IO}_{2}}$ and $\mathrm{S}_{\mathrm{pO}_{2}}$ in both groups. No differences in $\mathrm{F}_{\mathrm{IO}_{2}}$ or $\mathrm{S}_{\mathrm{pO}_{2}}$ were found between treatment groups either.

\section{Use of Sedatives}

No differences were found between 2 groups. During the 2-h period, only 3 subjects required sedatives (all dur- ing the first hour): 2 subjects in NP-H group (1 single bolus and 1 bolus plus continuous infusion of midazolam), and 1 subject in the H-NP group (bolus plus continuous infusion of midazolam).

\section{Discussion}

To our knowledge, this is the first randomized study comparing helmet-delivered CPAP and CPAP delivered via nasal prongs in young infants with moderate to severe respiratory syncytial virus bronchiolitis. The results reported here suggest that the helmet interface might be an alternative to nasal prongs to treat bronchiolitis in infants up to 3 months of age. The 2 groups were comparable in terms of severity, hypercapnia, and baseline vital signs. In addition, the crossover design of the study minimized the possible bias of age.

In our study, both CPAP systems seemed to be able to significantly decrease the clinical score shortly after CPAP initiation. This relief in the work of breathing was maintained throughout the study time in most cases (Fig. 2). Unsurprisingly, heart rate and breathing frequency significantly decreased after CPAP initiation, as described in previous studies. ${ }^{9,15,21}$ The slight differences seen in heart rate and breathing frequency evolution may be explained by the sample size. However, this response did not significantly differ between groups (Figs. 3 and 4).

The effectiveness of CPAP in moderately severe bronchiolitis has been reported in several studies. In a randomized controlled trial, Thia et $\mathrm{al}^{2}$ showed increased effec- 


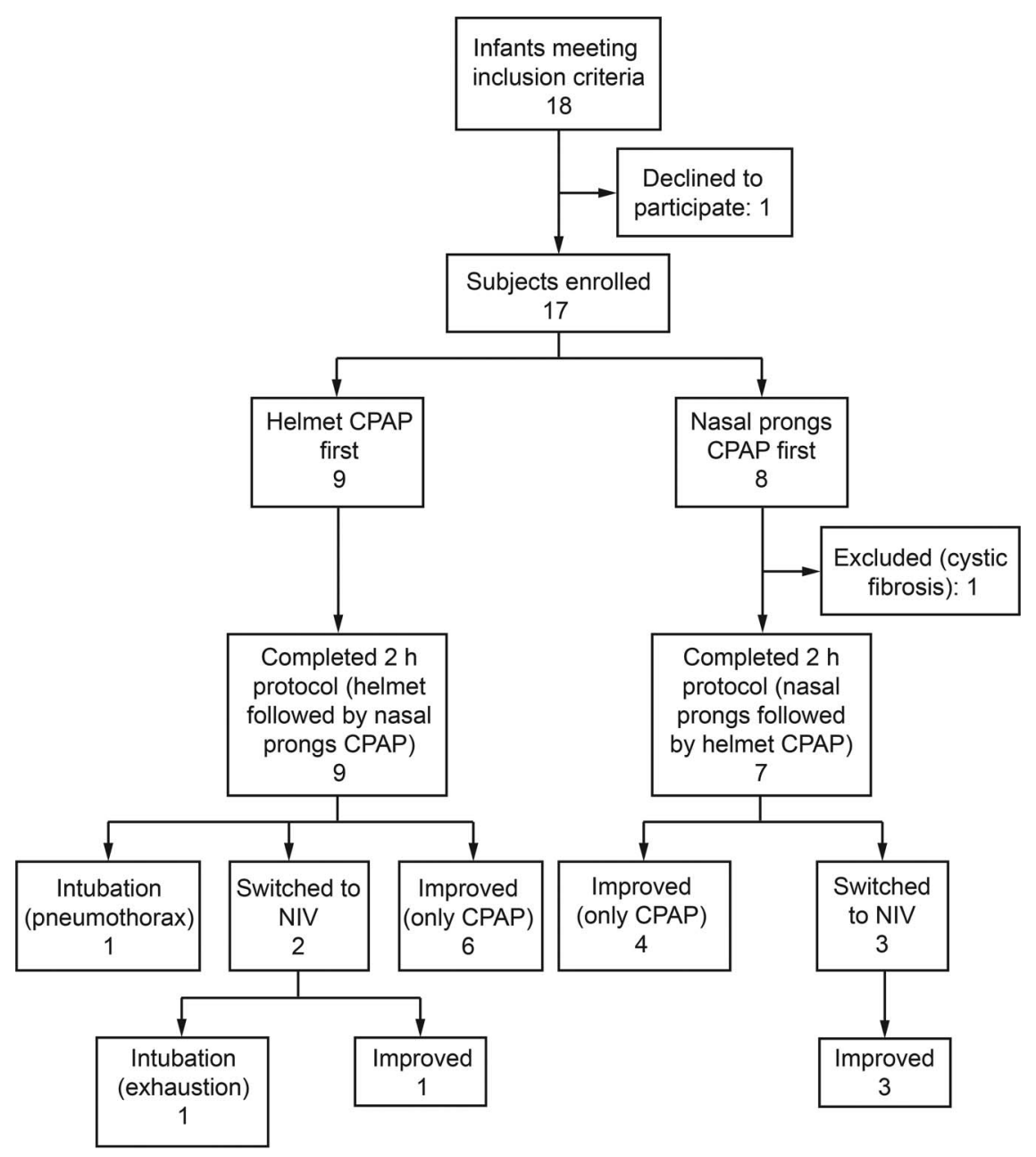

Fig. 1. Flow chart. NIV = noninvasive ventilation.

tiveness in reducing $\mathrm{P}_{\mathrm{CO}_{2}}$ when CPAP was delivered initially in comparison with initial spontaneous breathing. Cambonie et $\mathrm{al}^{3}$ reported the efficacy of nasal-prong CPAP in unloading respiratory muscles and relieving respiratory distress. Martinón-Torres et al ${ }^{16}$ also found CPAP to be effective in diminishing $\mathrm{CO}_{2}$ values and improving clinical score. These properties seemed to be enhanced by the addition of heliox. Furthermore, other studies (not randomized controlled trials) have shown a decrease in the intubation rate after introducing noninvasive respiratory support (studies cover NIV and CPAP) approaches in infants with severe bronchiolitis. ${ }^{22-24}$ Proposed reasons for these positive effects of CPAP are diverse. This type of respiratory support has a widening effect on the terminal airways, which prevents airway collapse, recruits underventilated areas, and ultimately improves alveolar ventilation., ${ }^{2,3}$ This support also seems to reduce airway resistance, which could contribute to a decrease in the work load on the inspiratory muscles. Thus, CPAP is able to reduce the work of breathing and improve ventilation-perfusion mismatch.
Essouri et $\mathrm{al}^{25}$ found that the optimal CPAP level in infants with hypercapnic bronchiolitis was $7 \mathrm{~cm} \mathrm{H}_{2} \mathrm{O}$. We used a lower CPAP level of about $6 \mathrm{~cm} \mathrm{H}_{2} \mathrm{O}$, similar to the findings of Milesi et al. ${ }^{4}$ The need for further respiratory support may seem high in our study (6 of 16 subjects, $37.5 \%$ ). This might be related to the exclusive inclusion of infants $<3$ months old, as young age is one of the most relevant risk factors. ${ }^{26}$ However, only 2 subjects were eventually intubated, and this intubation rate of $12 \%$ was similar to previous studies ${ }^{15,21}$ or even lower. ${ }^{23,24,26}$ In any case, the small sample size does not allow further conclusions to be made regarding this point.

Helmet-delivered CPAP has been increasing recently in adult and pediatric populations. ${ }^{7-12,14,27-35}$ Most studies have shown that the helmet has an increased tolerability and effectiveness, ${ }^{32}$ with fewer adverse effects than other interfaces. ${ }^{7-9,13,36}$ However, other researchers have reported better patient-ventilator synchrony with a face mask than with a helmet, ${ }^{28,29,34}$ although this is of utmost importance when delivering pressure support NIV, and not with CPAP. ${ }^{28,37}$ 


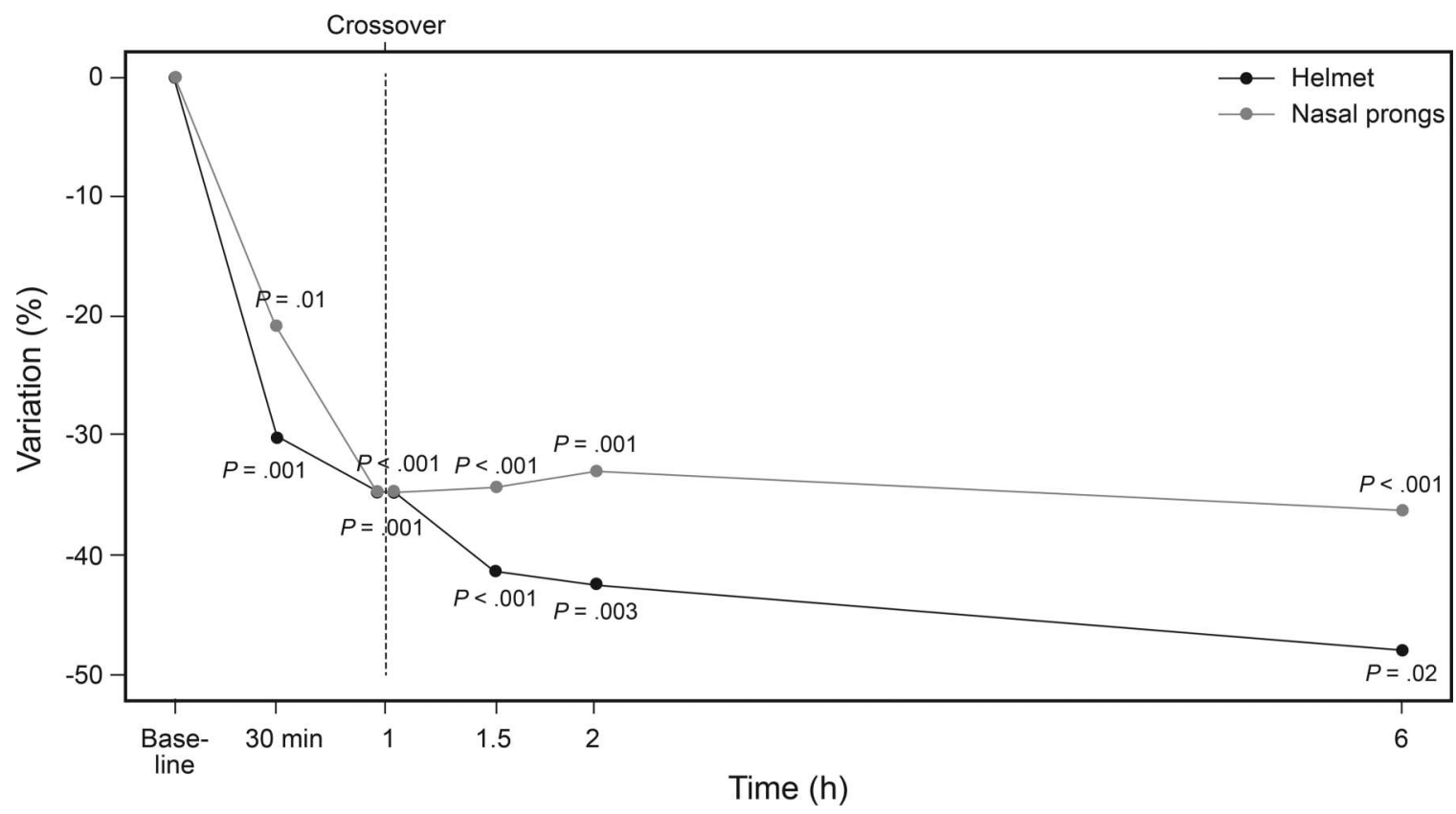

Fig. 2. Evolution of percentage variation of the M-WCAS. Note the similar decrease in both groups in the first part of crossover study (30 min and $60 \mathrm{~min}) . P$ values show changes of variation percentage of M-WCAS from initial value. No differences were found between the groups. Helmet $=$ helmet CPAP followed by nasal prong CPAP. Nasal prongs $=$ nasal prong CPAP followed by helmet CPAP. M-WCAS $=$ Modified Wood's Clinical Asthma Score.

In comparison with nasal prongs, the helmet has some theoretical advantages. It allows a good interaction with the environment without limiting an infant's head movements, reducing the risk of dislodging the interface; it avoids fluctuations in the delivered pressure due to oral leaks; and it avoids nasal injuries. During the 2-h study, tolerance was good in both groups (only 3 children required sedatives), and no differences were found. This

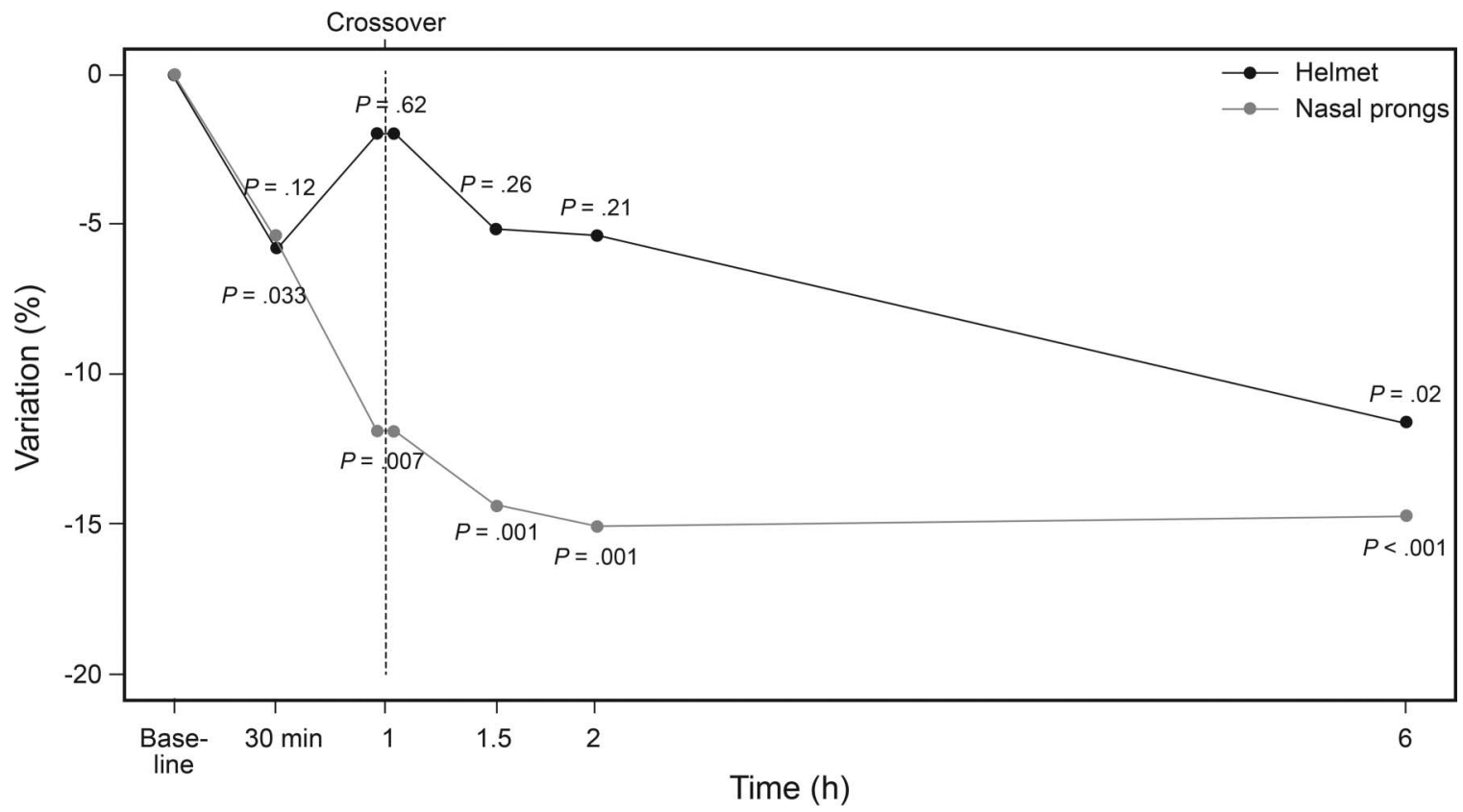

Fig. 3. Changes in percentage variation of heart rate. $P$ values show variation percentage of heart rate from initial value. No statistically significant differences were found between the groups. Helmet $=$ helmet CPAP followed by nasal prong CPAP. Nasal prongs $=$ nasal prong CPAP followed by helmet CPAP. 


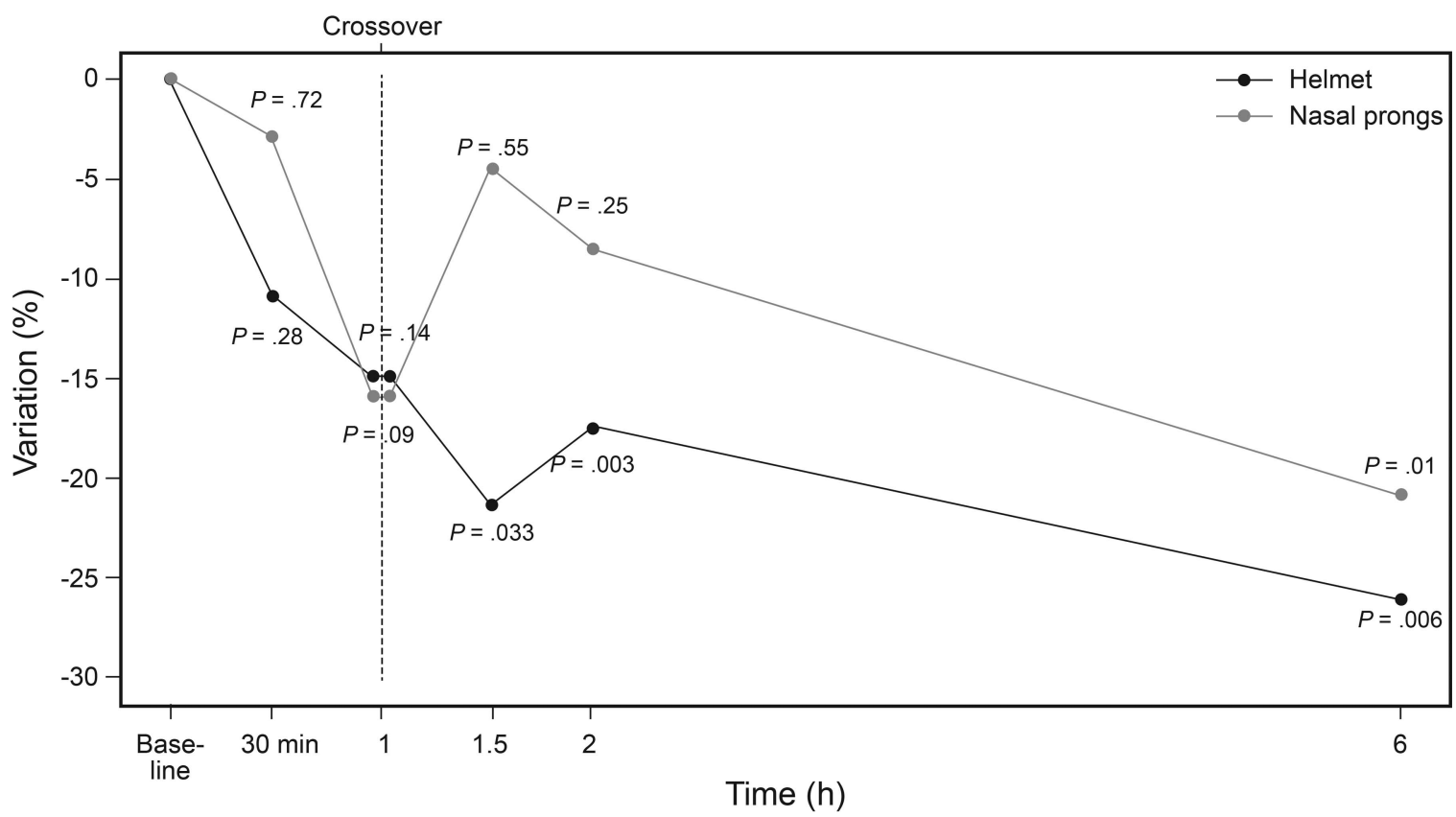

Fig. 4. Changes in percentage variation of breathing frequency. $P$ values show variation percentage of breathing frequency from initial value. No statistically significant differences were found between the groups. Note the significant increase in variation percentage of breathing frequency at $90 \mathrm{~min}$ in the helmet group. Helmet = helmet CPAP followed by nasal prong CPAP. Nasal prongs $=$ nasal prong CPAP followed by helmet CPAP.

could be due to the fact that most of these advantages might be more important in the long term, allowing prolonged treatments when using the helmet, as suggested by other authors. ${ }^{7,9}$ Despite these advantages, it should be taken into account that noise level might be greater when employing a helmet, ${ }^{11}$ and that the use of a pacifier is challenging, although not impossible.

We used a heated humidifier in all cases. According to some authors, adding this system is advisable for CPAP delivery. ${ }^{38,39}$ Some experts have described the intermittent use of a heated humidifier to avoid overheating of gases and rain-out effect. ${ }^{9}$ Heating and humidifying the inspiratory fresh gas flow might help avoid the development of atelectasis secondary to mucous plugging. We also placed a soft cushion inside the helmet for each subject to avoid pressure sores (we had none). Milesi et al ${ }^{11}$ used a small cushion in the same way after finding pressures sores at the skull base in 3 of the first 6 subjects included in their study.

An important issue that should be addressed when using helmet-delivered CPAP is $\mathrm{CO}_{2}$ rebreathing. ${ }^{11}$ The volume of the helmet does not directly affect the inspired partial pressure of $\mathrm{CO}_{2}$. The main determinants of inspired partial pressure of $\mathrm{CO}_{2}$ are the amount of $\mathrm{CO}_{2}$ produced by the patient and the flow of fresh gas passing through the helmet. ${ }^{40}$ In the absence of air leaks, $\mathrm{CO}_{2}$ rebreathing occurs. For this reason, helmet-delivered CPAP should not be performed with closed-circuit (eg, double-limb) ventilators. ${ }^{39}$ However, some experimental studies did not find signifi- cant differences regarding the effective dead space volume among different interfaces (including the helmet). ${ }^{41} \mathrm{We}$ therefore used high gas flows $(>30 \mathrm{~L} / \mathrm{min})$ with helmetdelivered CPAP to avoid rebreathing, as other authors do. ${ }^{9}$

This study has several limitations. The small size of the sample precludes any definitive conclusions. However, it was sufficient to suggest similar clinical response to both methods of CPAP in this special group of subjects. Lack of a washout period between interface changes may have had a carryover effect on the second part of the study. This possible bias was lowered, however, because it was present in both groups. Furthermore, we decided not to establish a washout period because we thought that the clinical situation of a critically ill infant might worsen acutely due to withdrawing CPAP therapy for some time. The nonblinded design of the study is another limitation, which cannot be avoided for obvious reasons. In addition, the use of sedatives was based on caregivers' impressions, not on validated scales. Finally, it would have been very informative to have recorded esophageal pressure, so that we could quantify the relief in the work of breathing with each interface. ${ }^{25,26}$

This study has some strengths. It is the first randomized study comparing CPAP delivered via helmet and nasal prongs in infants with moderate to severe bronchiolitis. This study focuses on a very specific and challenging population of small infants with bronchiolitis. This type of patient represents one of the more time- and resourceconsuming patients during winter periods in most pediatric 
ICUs, and thus, our study might be of some help for many physicians. In conclusion, our results suggest that CPAP delivered via helmet or via nasal prongs has similar efficacy in very small infants with moderate to severe bronchiolitis.

\section{ACKNOWLEDGMENTS}

The authors acknowledge the assistance of the medical and nursing staff of our pediatric ICU.

\section{REFERENCES}

1. Ralston SL, Lieberthal AS, Meissner HC, Alverson BK, Baley JE, Gadomski AM, et al. Clinical practice guideline: the diagnosis, management, and prevention of bronchiolitis. Pediatrics 2014;134(5): e1474-e1502.

2. Thia LP, McKenzie SA, Blyth TP, Minasian CC, Kozlowska WJ, Carr SB. Randomised controlled trial of nasal continuous positive airways pressure (CPAP) in bronchiolitis. Arch Dis Child 2008; 93(1):45-47.

3. Cambonie G, Milesi C, Jaber S, Amsallem F, Barbotte E, Picaud JC, Matecki S. Nasal continuous positive airway pressure decreases respiratory muscles overload in young infants with severe acute viral bronchiolitis. Intensive Care Med 2008;34(10):1865-1872.

4. Milesi C, Matecki S, Jaber S, Mura T, Jacquot A, Pidoux O, et al. 6 $\mathrm{cmH} 2 \mathrm{O}$ continuous positive airway pressure versus conventional oxygen therapy in severe viral bronchiolitis: a randomized trial. Pediatr Pulmonol 2013;48(1):45-51.

5. Buettiker V, Hug MI, Baenziger O, Meyer C, Frey B. Advantages and disadvantages of different nasal CPAP systems in newborns. Intensive Care Med 2004;30(5):926-930.

6. De Paoli AG, Davis PG, Faber B, Morley CJ. Devices and pressure sources for administration of nasal continuous positive airway pressure (NCPAP) in preterm neonates. Cochrane Database Syst Rev 2008;(1):CD002977.

7. Chidini G, Calderini E, Cesana BM, Gandini C, Prandi E, Pelosi P. Noninvasive continuous positive airway pressure in acute respiratory failure: helmet versus facial mask. Pediatrics 2010;126(2):e330-e336.

8. Chidini G, Calderini E, Pelosi P. Treatment of acute hypoxemic respiratory failure with continuous positive airway pressure delivered by a new pediatric helmet in comparison with a standard full face mask: a prospective pilot study. Pediatr Crit Care Med 2010; 11(4):502-508.

9. Chidini G, Piastra M, Marchesi T, De Luca D, Napolitano L, Salvo I, et al. Continuous positive airway pressure with helmet versus mask in infants with bronchiolitis: an RCT. Pediatrics 2015;135(4):e868e875.

10. Codazzi D, Nacoti M, Passoni M, Bonanomi E, Sperti LR, Fumagalli R. Continuous positive airway pressure with modified helmet for treatment of hypoxemic acute respiratory failure in infants and a preschool population: a feasibility study. Pediatr Crit Care Med 2006; 7(5):455-460.

11. Milesi C, Ferragu F, Jaber S, Rideau A, Combes C, Matecki S, et al. Continuous positive airway pressure ventilation with helmet in infants under 1 year. Intensive Care Med 2010;36(9):1592-1596.

12. Vitaliti G, Vitaliti MC, Finocchiaro MC, Di Stefano VA, Pavone P, Matin N, et al. Randomized comparison of helmet CPAP versus high-flow nasal cannula oxygen in pediatric respiratory distress. Respir Care 2017;62(8):1036-1042.

13. Trevisanuto D, Grazzina N, Doglioni N, Ferrarese P, Marzari F, Zanardo V. A new device for administration of continuous positive airway pressure in preterm infants: comparison with a standard nasal
CPAP continuous positive airway pressure system. Intensive Care Med 2005;31(6):859-864.

14. Mayordomo-Colunga J, Medina A, Rey C, Concha A, Los Arcos M, Menéndez S. Helmet-delivered continuous positive airway pressure with heliox in respiratory syncytial virus bronchiolitis. Acta Paediatr 2010;99(2):308-311.

15. Mayordomo-Colunga J, Medina A, Rey C, Los Arcos M, Concha A, Menéndez S. [Success and failure predictors of non-invasive ventilation in acute bronchiolitis]. An Pediatr (Barc) 2009;70(1):34-39.

16. Martinon-Torres F, Rodriguez-Nunez A, Martinon-Sanchez JM. Nasal continuous positive airway pressure with heliox versus air oxygen in infants with acute bronchiolitis: a crossover study. Pediatrics 2008;121(5):e1190-e1195.

17. Soong WJ, Hwang B, Tang RB. Continuous positive airway pressure by nasal prongs in bronchiolitis. Pediatr Pulmonol 1993;16(3):163166.

18. Martinon-Torres F, Rodriguez-Nunez A, Martinon-Sanchez JM. Heliox therapy in infants with acute bronchiolitis. Pediatrics 2002; 109(1):68-73.

19. Patroniti N, Foti G, Manfio A, Coppo A, Bellani G, Pesenti A. Head helmet versus face mask for non-invasive continuous positive airway pressure: a physiological study. Intensive Care Med 2003;29(10): 1680-1687.

20. Grizzle JE. The two-period change-over design and its use in clinical trials. Biometrics 1965;21:467-480.

21. Mayordomo-Colunga J, Medina A, Rey C, Díaz JJ, Concha A, Los Arcos M, Menéndez S. Predictive factors of non invasive ventilation failure in critically ill children: a prospective epidemiological study. Intensive Care Med 2009;35(3):527-536.

22. Essouri S, Laurent M, Chevret L, Durand P, Ecochard E, Gajdos V, et al. Improved clinical and economic outcomes in severe bronchiolitis with pre-emptive nCPAP ventilatory strategy. Intensive Care Med 2014;40(1):84-91.

23. Ganu SS, Gautam A, Wilkins B, Egan J. Increase in use of noninvasive ventilation for infants with severe bronchiolitis is associated with decline in intubation rates over a decade. Intensive Care Med 2012;38(7):1177-1183.

24. Javouhey E, Barats A, Richard N, Stamm D, Floret D. Non-invasive ventilation as primary ventilatory support for infants with severe bronchiolitis. Intensive Care Med 2008;34(9):1608-1614.

25. Essouri S, Durand P, Chevret L, Balu L, Devictor D, Fauroux B, Tissières P. Optimal level of nasal continuous positive airway pressure in severe viral bronchiolitis. Intensive Care Med 2011;37(12): 2002-2007.

26. Mansbach JM, Piedra PA, Stevenson MD, Sullivan AF, Forgey TF, Clark S, et al. Prospective multicenter study of children with bronchiolitis requiring mechanical ventilation. Pediatrics 2012;130(3): e492-e500.

27. Baudin F, Pouyau R, Cour-Andlauer F, Berthiller J, Robert D, Javouhey E. Neurally adjusted ventilator assist (NAVA) reduces asynchrony during non-invasive ventilation for severe bronchiolitis. Pediatr Pulmonol 2015;50(12):1320-1327.

28. Conti G, Gregoretti C, Spinazzola G, Festa O, Ferrone G, Cipriani F, et al. Influence of different interfaces on synchrony during pressure support ventilation in a pediatric setting: a bench study. Respir Care 2015;60(4):498-507.

29. Costa R, Navalesi P, Spinazzola G, Ferrone G, Pellegrini A, Cavaliere $\mathrm{F}$, et al. Influence of ventilator settings on patient-ventilator synchrony during pressure support ventilation with different interfaces. Intensive Care Med 2010;36(8):1363-1370.

30. Isgro S, Zanella A, Sala C, Grasselli G, Foti G, Pesenti A, Patroniti N. Continuous flow biphasic positive airway pressure by helmet in patients with acute hypoxic respiratory failure: effect on oxygenation. Intensive Care Med 2010;36(10):1688-1694. 
31. Olivieri C, Longhini F, Cena T, Cammarota G, Vaschetto R, Messina A, et al. New versus conventional helmet for delivering noninvasive ventilation: a physiologic, crossover randomized study in critically ill patients. Anesthesiology 2016;124(1):101-108.

32. Patel BK, Wolfe KS, Pohlman AS, Hall JB, Kress JP. Effect of noninvasive ventilation delivered by helmet vs face mask on the rate of endotracheal intubation in patients with acute respiratory distress syndrome: a randomized clinical trial. JAMA 2016;315(22):24352441.

33. Piastra M, De Luca D, Pietrini D, Pulitanò S, D’Arrigo S, Mancino A, Conti G. Noninvasive pressure-support ventilation in immunocompromised children with ARDS: a feasibility study. Intensive Care Med 2009;35(8):1420-1427.

34. Vargas F, Thille A, Lyazidi A, Campo FR, Brochard L. Helmet with specific settings versus facemask for noninvasive ventilation. Crit Care Med 2009;37(6):1921-1928.

35. Zaramella P, Freato F, Grazzina N, Saraceni E, Vianello A, Chiandetti L. Does helmet CPAP reduce cerebral blood flow and volume by comparison with infant flow driver CPAP in preterm neonates? Intensive Care Med 2006;32(10):1613-1619.
36. Rocco M, Dell'Utri D, Morelli A, Spadetta G, Conti G, Antonelli M, Pietropaoli P. Noninvasive ventilation by helmet or face mask in immunocompromised patients: a case-control study. Chest 2004; 126(5):1508-1515.

37. Essouri S, Nicot F, Clement A, Garabedian EN, Roger G, Lofaso F, Fauroux B. Noninvasive positive pressure ventilation in infants with upper airway obstruction: comparison of continuous and bilevel positive pressure. Intensive Care Med 2005;31(4):574-580.

38. Chiumello D, Chierichetti M, Tallarini F, Cozzi P, Cressoni M, Polli $F$, et al. Effect of a heated humidifier during continuous positive airway pressure delivered by a helmet. Crit Care 2008;12(2):R55.

39. Nava $S$, Navalesi $P$, Gregoretti C. Interfaces and humidification for noninvasive mechanical ventilation. Respir Care 2009;54(1):71-84

40. Mojoli F, Iotti GA, Gerletti M, Lucarini C, Braschi A. Carbon dioxide rebreathing during non-invasive ventilation delivered by helmet: a bench study. Intensive Care Med 2008;34(8):1454-1460.

41. Fodil R, Lellouche F, Mancebo J, Sbirlea-Apiou G, Isabey D, Brochard L, Louis B. Comparison of patient-ventilator interfaces based on their computerized effective dead space. Intensive Care Med 2011;37(2):257-262. 